\title{
A IMPRENSA OPERÁRIA E A HISTÓRIA DA EDUCAÇÃO: UMA ANÁLISE DAS CONTRIBUIÇÕES DOS JORNAIS O LABOR E O CONFEDERAL PARA A HISTÓRIA DA EDUCAÇÃO NOS ANOS INICIAIS DE BELO HORIZONTE
}

\author{
Renata Garcia Campos Duarte* \\ lattes.cnpq.br/6915394554075962
}

\begin{abstract}
Resumo: Este artigo tem como objetivo discutir a importância da utilização de impressos operários enquanto fonte para as pesquisas em história da educação, analisando alguns debates e ideias educacionais presentes em dois jornais operários de origem associativa: $O$ Labor, da Confederação Auxiliadora dos Operários, e $O$ Confederal, do Centro Confederativo dos Operários. As associações responsáveis pelos periódicos foram constituídas nos primeiros anos de existência de Belo Horizonte, cidade construída para sediar a nova capital do Estado de Minas Gerais. Os impressos operários, por sua vez, são entendidos em suas particularidades tendose em vista as suas características, os quais divulgavam algumas ideias e debates, como os referentes ao campo educacional. A partir da análise dos jornais foi apurada a existência de demandas e propostas por educação para todas as classes sociais, visto que o ensino em Belo Horizonte não era ofertado a todos, ou se era oferecido, não alcançava as classes sociais menos favorecidas.
\end{abstract}

Palavras-chave: Associações operárias; Belo Horizonte; Educação; História da educação; Imprensa operária.

\section{THE WORKING CLASS PRESS AND THE HISTORY OF EDUCATION: AN ANALYSIS OF THE CONTRIBUTIONS OF THE NEWSPAPERS THE LABOR AND THE CONFEDERAL TO THE HISTORY OF EDUCATION IN THE INITIAL YEARS OF BELO HORIZONTE}

\begin{abstract}
This article aims to discuss the importance of the use of working class press as a source for research in the history of education, analyzing some debates and educational ideas present in two workers' newspapers of associative origin: The Labor, of the Auxiliary Confederation of Workers, and The Confederal, of the Confederative Center for Workers. The associations responsible for the periodicals were constituted in the first years of existence of Belo Horizonte, city built to host the
\end{abstract} * Doutoranda em Educação pela Universidade Federal de Minas Gerais, UFMG
(Brasil). Contato: renatagcd@yahoo.com.br. 
new capital of the State of Minas Gerais. The working class periodicals, in turn, are understood in their particularities in view of their characteristics, which disseminated some ideas and debates, such as those concerning the educational field. From the analysis of the newspapers, the existence of demands and proposals for education for all social classes was verified, whereas the education in Belo Horizonte was not offered to all, or if it was offered, it did not reach the less favored social classes.

Keywords: Workers associations; Belo Horizonte; Education; History of education; Working class press.

\section{Introdução: imprensa, impressos operários e História da Educação}

Este artigo objetiva discutir a relevância da utilização de impressos - particularmente os impressos operários - para as pesquisas em história da educação. Nesse sentido, aborda a criação de duas associações operárias em Belo Horizonte, a Confederação Auxiliadora dos Operários e o Centro Confederativo dos Operários, a produção e edição de seus impressos, respectivamente $O$ Labor e $O$ Confederal, seu funcionamento, e apontamento de alguns debates e ideias educacionais neles contidas.

A imprensa é uma das fontes mais utilizadas por diversos campos de estudos históricos. Se algum dia foi considerada uma fonte com pouca credibilidade, nas últimas décadas é frequentemente manuseada, principalmente nas ciências humanas, seja como fonte, como objeto de pesquisa, ou como suporte didático-pedagógico na sala de aula.

Nessa conjuntura, crescentemente as pesquisas em história da educação usam a imprensa como fonte e objeto de pesquisa, especialmente a chamada imprensa pedagógica, produzida por estudantes, professores, autoridades ou órgãos educacionais competentes, cuja temática associava-se às questões educacionais.

Carlos Henrique de Carvalho, José Carlos Souza Araujo e Wenceslau Gonçalves Neto (2002) afirmam que a imprensa normalmente é 
empregada pela história da educação enquanto um recurso complementar. Porém, assinalam que "nos últimos anos vem contribuindo sobremaneira para novos estudos ligados ao campo educacional" (CARVALHO; ARAUJO; NETO, 2002, p. 72).

Conforme Maria Helena Camara Bastos (2002, p. 153), a imprensa é um "instrumento privilegiado de pesquisa para construção do conhecimento em história da educação". Os impressos em geral, não apenas a imprensa pedagógica, são entendidos por Bastos como um mecanismo educativo. A partir de sua análise documental, diferentes aspectos sociais e políticos, práticas e pensamentos educacionais se revelam.

A imprensa pedagógica - jornais, boletins, revistas, magazines feita por professores para professores, feita para alunos por seus pares ou professores, feita pelo Estado ou por outras instituições - sindicatos, partidos políticos, associações de classe, Igreja - contém e oferece muitas perspectivas para a compreensão da história da educação e do ensino. Sua análise possibilita avaliar a política das organizações, as preocupações sociais, os antagonismos e as filiações ideológicas, as práticas educativas. (BASTOS, 2002, p. 153).

Nessa perspectiva, Luciano Mendes de Faria Filho, a despeito de apresentar como pressuposto pesquisas sobre a história da educação mineira do século XIX, explana a respeito de algumas fontes documentais importantes para o campo de pesquisa, dentre as quais destaca os jornais como relevante estratégia educativa.

Também aqui, como em outros lugares do mundo, o jornal foi visto como uma importante estratégia de construção de consensos, de propaganda política e religiosa, de produção de novas sensibilidades, maneiras e costumes. Sobretudo os jornais foram vistos como importante estratégia educativa. (FARIA FILHO, 2002, p. 134).

Tanto na perspectiva de Faria Filho como na de Bastos, o papel da imprensa é maior que narrar objetivamente os acontecimentos. Ela é ativa, constrói consensos, expõe tensões, divulga ideias, produz novas sensibilidades.

Essa acepção conduz a uma importante pesquisa de Darnton (1996) 
que apresenta novas abordagens ao estudo da Revolução Francesa a partir da ênfase da imprensa como agente, um ingrediente do acontecimento. Ao esboçar o papel das tipografias naquele contexto revolucionário menciona que historiadores se ocupam da imprensa como registro do acontecimento, quando, ao contrário, dava forma a esses, logo, deve ser redescoberta em sua dimensão constitutiva, pois agente dos acontecimentos.

Qual o papel que a tipografia desempenhou na Revolução Francesa? Os historiadores tratam em geral a palavra impressa como um registro do que aconteceu e não como um ingrediente do acontecimento. Mas a prensa tipográfica ajudou a dar formas aos eventos que registrava. Foi uma força ativa na história (...). (DARNTON, 1996, p. 15).

A imprensa, como fonte e objeto de estudo, segundo Darnton (1996), é mais ingrediente do processo do que simples registro dos acontecimentos, por isso, deve-se ter o cuidado para não a tomar como espelho da realidade.

Desse modo, conforme Heloísa de Faria Cruz e Maria do Rosário da Cunha Peixoto (2007), a imprensa deve ser compreendida enquanto força social indissociável das lutas sociais. Por conseguinte, os periódicos operários, ao mesmo tempo em que informavam os trabalhadores sobre assuntos diversificados, propuseram e agiram no processo de conquista de direitos políticos e sociais.

Como esta imprensa é adjetivada pelo vocábulo “operária”, deve-se discutir melhor as características que a faz ser delimitada enquanto tal. A princípio, a definição de "imprensa operária” parece elementar, contudo, algumas questões devem ser discutidas para melhor designar o termo.

Maria Nazareth Ferreira (1988, p. 5) inicialmente a define de modo objetivo, como a imprensa produzida por operários (operário é o emissor), ou a eles dirigida (operário é o receptor), ou aquela cujo conteúdo basicamente são os problemas da classe operária. Mas segundo a autora, essa definição é insuficiente porque "existe uma razoável quantidade de publicações que, apesar de não serem produzidas por operários, visam a esse público, abordam uma temática operária e 
expressam (...) reivindicações do operariado”. Dessa forma, a imprensa operária, igualmente, poderia ser objeto de outras classes sociais que pretendiam o operariado como alvo.

Ferreira (1988) aponta, ainda, outras características da imprensa operária, como sua frequente ligação com algumas formas de organização dos trabalhadores (partido, sindicato, agremiações), e a ausência de proprietário.

Francisco Foot Hardman e Victor Leonardi (1991), assim como Ferreira, percebem que os periódicos operários eram, muitas vezes, conectados a associações sindicais de categorias de trabalhadores. Acrescentam que, podendo pertencer a diferentes tendências de pensamento político (anarquista, anarcossindicalista, socialista ou sindicalista), era uma importante atividade político-cultural, ainda que os impressos fossem pequenos, de periodicidade irregular, e dependessem de subscrições por parte dos leitores.

Tinham existência semilegal, trazendo impresso muitas vezes o endereço da redação ou dos responsáveis para correspondência. Possuíam condições muito adversas de sobrevivência: além dos limites de ordem financeira, a ausência plena de liberdade de imprensa ocasionava problemas frequentes, como o empastelamento de várias redações pela polícia, em momentos agudos da luta de classes. (HARDMAN; LEONARDI, 1991, p. 256).

Tânia Regina de Luca reforça as ideias de Hardman e Leonardi no que diz respeito a ausência de periodicidade e necessidade de subscrições, e destaca outras características:

Agora não se tratava mais de lidar com jornais de cunho empresarial, capazes de influenciar a vida política, mas de manejar folhas sem periodicidade ou número de páginas definidas, feitas não por profissionais, mas por militantes abnegados, por vezes redigidas em língua estrangeira, sobretudo italiano e espanhol, impressas em pequenas oficinas, no formato permitido pelo papel e máquinas disponíveis, sem receita publicitária e que, no mais das vezes, contava com subscrição dos próprios leitores para sobreviver (...). (LUCA, 2006, p. 119). 
Como os outros autores, Maria Auxiliadora Guzzo Decca (1987, p. 98) percebe a imprensa operária enquanto importante prática política, "como órgãos de arregimentação, mobilização, conscientização e denúncia”. A autora diz que a imprensa operária constitui um documento que serve de contraponto às fontes ligadas ao poder instituído, uma vez que os jornais e revistas apresentavam a maneira como os operários viam os seus problemas, os quais "denunciaram as condições de vida do operariado, equacionaram seus problemas e propuseram formas de preservação de 'valores de classe' de acordo com suas concepções e visões políticas” (DECCA, 1987, p. 112). A partir da análise desses periódicos é possível perceber formas de luta e resistência organizadas para e pelos trabalhadores, e a diversidade de tendências políticas existentes no movimento operário.

Laura Antunes Maciel acrescenta que normalmente a imprensa operária é utilizada em estudos com a intenção de reconstruir as condições de vida e de trabalho dos operários, bem como os valores e as culturas operárias, a análise de formas de militância política, e a mobilização da classe. Mas esta imprensa deve ser compreendida como uma "esfera significativa da luta social", uma vez que

O domínio da palavra escrita e a possibilidade de divulgá-la por meio de periódicos significavam, para os populares, a conquista de um recurso até então monopolizado por poucos, comprometidos com a manutenção ou recriação do status quo. (MACIEL, 2008a, p. 01).

Dessa maneira, fazer imprensa para os trabalhadores era a possibilidade de mostrarem suas versões e experiências, que eram alternativas às versões hegemônicas. Essa imprensa afirmava sujeitos sociais marginalizados pelo discurso dominante da grande imprensa. Para Maciel são vários os sentidos de se atuar através da imprensa enquanto prática social importante para os trabalhadores das cidades, tais como "elaborar sentidos para as próprias ações e para as dos outros, difundir projetos e perspectivas próprias ao grupo ou intervir em assuntos considerados de interesse coletivo, público" (MACIEL, 2008b, p. 115). 
Conforme Ilka Stern Coben (2013), o discurso da imprensa operária propagava ideias e valores da classe operária, tornava pública as relações de trabalho que ocorriam no interior das fábricas, e era um eficiente meio de comunicação entre os membros das associações operárias. Além disso, afirma que esse discurso

(...) constituía verdadeiro contraponto à visão edulcorada do progresso oferecida pelas revistas de variedade, na medida em que abordava os árduos temas debatidos nos incontáveis jornais operários produzidos entre 1890 e 1920/1930. (COBEN, 2013, p. 120).

Astrojildo Pereira (1990) menciona que, com o advento da República, o movimento operário se desenvolveu e os impressos operários cresceram de importância. Entretanto, ressalta a dificuldade de se estabelecer uma relação completa de títulos, porque muitos periódicos operários de alguns estados tiveram curta duração, surgiram e desapareceram rapidamente.

Alguns autores, como Pereira e Ferreira, chegam a atrelar a história da imprensa operária à história da classe operária. De acordo com Pereira (1990, p. 88), "a história da imprensa operária é a própria história da classe operária, das suas lutas, dos seus sofrimentos, das suas esperanças”. Já Ferreira (1988, p. 06) salienta que a imprensa operária deve ser avaliada em conjunto do movimento operário, pois "ambos estão inter-relacionados através das lutas da classe trabalhadora na construção de sua história”.

Destarte, a imprensa operária pode ser definida como um conjunto de periódicos (jornais, revistas, folhetos, panfletos) produzidos sobretudo por operários e/ou a eles destinados, em grande medida, vinculados a associações, cujas tendências políticas, e as suas principais contendas e tensões, eram expressas em suas páginas. Ademais, os impressos operários se caracterizavam pela indefinição da periodicidade, curta duração, e necessidade de subscrições por parte dos leitores para sua conservação. Essas características estão presentes tanto em $O$ Labor como em $O$ Confederal, ambos produzidos por associações operárias de Belo Horizonte, entre 1905 e 1907. 
Assim sendo, é possível estudar a história da classe operária e suas principais reivindicações, manifestações, conquistas, tendências políticas, tal como o modo como os trabalhadores compreendiam a sociedade, buscavam espaços e apresentavam projetos alternativos, a partir da utilização da imprensa operária enquanto relevante fonte e objeto de pesquisas acadêmicas, dentre as quais aquelas concernentes à história da educação.

\section{Confederação Auxiliadora dos Operários \\ E Centro Confederativo dos Operários \\ de Belo Horizonte: criação, impressos e demandas educacionais}

Em 1893, o Congresso Mineiro resolveu pela transferência da localidade da capital do Estado de Minas Gerais, então situada na cidade de Ouro Preto. Os argumentos para essa alteração foram os mais distintos: desde a inadequação geográfica da antiga capital, até a necessidade de ajustamento ao novo regime político nacional, visto que Ouro Preto era tida como "atrasada", símbolo do império e do escravismo. Vários locais foram indicados, e após debates e disputas, o Congresso optou pelo Curral del-Rei. Essa opção foi feita a partir de princípios da racionalidade científica, levando-se em conta a "lógica de custos menores e a lógica de espaço do futuro" (VEIGA, 2002, p. 70).

A escolha também indicava uma questão político-econômica. Por encontrar-se localizado em região mais central, o Curral del-Rei era uma boa opção para favorecer o equilíbrio político e econômico, unindo diversas regiões econômicas de Minas Gerais. Nesse contexto, Eliana de Freitas Dutra ressalta a emergência de novas forças econômicas no Estado como um dos fatores impulsionadores da transferência da capital:

A transferência da capital mineira de Ouro Preto para outro local não tinha outra razão a não ser retirar a capital da decadente e antiga zona de mineração para atender outras zonas mais dinâmicas economicamente, como a Mata e o Sul 
que se desenvolveram graças à produção e exportação de café. (DUTRA, 1988, p. 52).

Em fevereiro de 1894 foi instituída a Comissão Construtora da Nova Capital que, no mês seguinte à sua criação, deu início as obras da nova capital. ${ }^{1}$ Em dezembro de 1897, durante o governo de Bias Fortes, a capital estabeleceu-se na então chamada Cidade de Minas (antigo Curral del-Rei). Somente com a lei $\mathrm{n}^{0}$ 302, de 11 de julho de 1901, a capital foi oficializada com o nome de Belo Horizonte.

Para construção da nova capital foi necessário empregar mão de obra hábil e suficiente, donde percebe-se a importância dos operários, muitos dos quais migrantes de outras regiões de Minas Gerais, do país, e de demais nações. ${ }^{2}$ Há de se destacar que o processo de construção e desenvolvimento da cidade capital, e a necessidade e formas de utilização da mão de obra em diferentes setores econômicos (construção, comércio, indústria) no decorrer do período analisado propiciou a organização do operariado em associações com as mais distintas finalidades: socorro mútuo, cooperativas, sindicatos, associações de classe, etc. Em geral, essas visavam proteger e defender os trabalhadores quando não haviam leis que os amparassem. 3

Com esses objetivos foram criadas algumas associações operárias nas primeiras décadas de existência de Belo Horizonte, como as aqui destacadas, que com seus impressos, contribuíram para informar e lutar pelos direitos dos trabalhadores.

\footnotetext{
${ }^{1}$ A Comissão Construtora da Nova Capital foi extinta em 1898, ano seguinte a inauguração da nova capital. As obras da cidade foram assumidas pela Secretaria da Agricultura.

2 Segundo Dutra (1988), os imigrantes - principalmente italianos - foram figuras importantes nas obras de construção de Belo Horizonte. Muitos deles eram trabalhadores qualificados do setor da construção civil. A autora afirma que nos anos 1920, $8,6 \%$ da população da capital mineira era composta por imigrantes.

3 É importante ressaltar que o Ministério do Trabalho foi criado em 1930, durante o governo de Getúlio Vargas, o qual foi responsável por unificar a legislação trabalhista na Consolidação das Leis do Trabalho (CLT) em 1943. Todavia, antes disso, algumas leis haviam sido conquistadas pelos trabalhadores de modo temporalmente esparso e localizado em determinados estados brasileiros.
} 
Em março de 1905 foi criada a Confederação4 Auxiliadora dos Operários, que buscava, além de fortalecer o operariado, filantropia

Figura 1 - Primeira página de $O$ Labor, de 18/6/1905. Fonte: CONFEDERAÇÃO AUXILIADORA DOS OPERÁRIOS DO ESTADO DE MINAS GERAIS. $O$ Labor, Belo Horizonte, ano I, n. 1, 18 jun. 1905, p. 1.

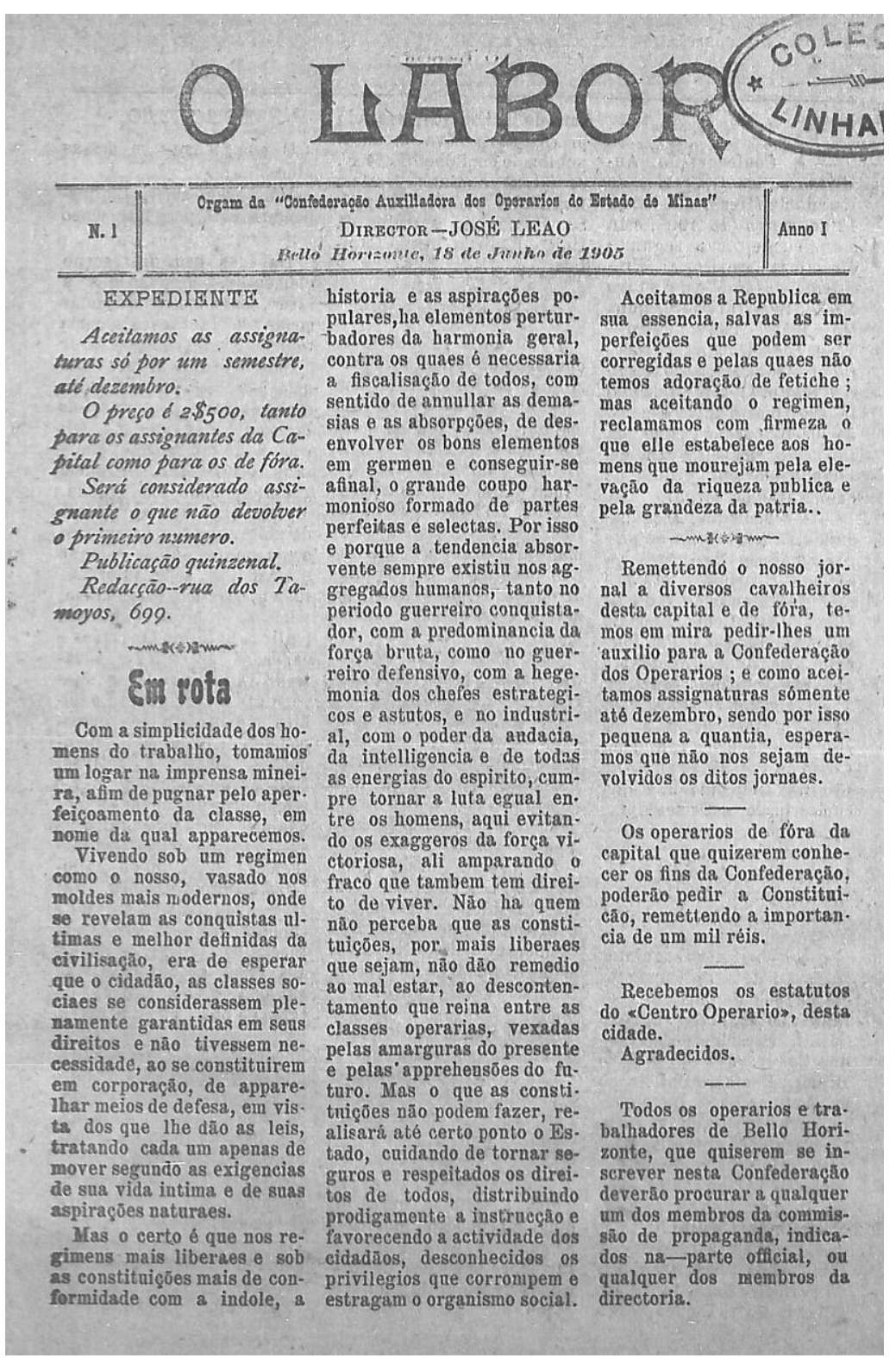
(auxílios materiais aos sócios), sociabilidade, instrução (Liceu de Artes e Ofícios e aulas noturnas na sede), ordem e progresso. A Confederação se posicionava "pela tutela do operariado por parte do Poder Público, que cuidaria de conseguir a harmonia do corpo social". (FARIA; GROSSI, 1982, p. 189). Dessa maneira, a Confederação aceitava o regime republicano, por isso não apresentava ideias contrárias ao governo e características revolucionárias. Ao contrário, suas críticas e lutas por direitos se realizavam dentro dos limites governamentais, como se observa nos estatutos, cujo um dos fins da Confederação era o de "empregar todos os

4 Segundo Dutra (1988), apesar do nome "Confederação", a Confederação Auxiliadora dos Operários não reunia sindicados, mas sim trabalhadores independentes diversos. 
meios possíveis de resolver qualquer divergência entre operários e industriais ou chefes". 5 Conforme Dutra:

Antes de 1920 chegou a se constituir como uma tendência organizatória do movimento operário de Belo Horizonte. A Confederação participou do Congresso Operário Mineiro, realizado em 2 de abril de 1907 em Sabará, onde foram vitoriosas as proposições reformistas; atendeu também a convocações da Liga Operária para comemorações do $1^{\circ}$ de maio de 1912, enviou telegramas de congratulações ao $2^{\circ}$ Congresso Operário de 1912 e apoiou todas as iniciativas do movimento sindical católico durante a década de 20. (DUTRA, 1988, p. 118).

$O$ Labor era a publicação quinzenal desta associação, teve 12 edições publicadas entre os anos 1905 e 1906, sendo seu redator o presidente da Confederação, José Leão. O jornal divulgava informações sobre a Confederação, empenhava-se pelo direito dos operários dentro dos marcos republicanos, apresentava as últimas notícias sobre o movimento operário em outras regiões do Brasil, bem como anunciava recebimento de outros periódicos, veiculava crônicas e contos.

Em $O$ Labor a carência de instrução primária era compreendida como uma das razões para o atraso brasileiro. Nas páginas do jornal a desorganização do ensino primário - poucas escolas, sem preceitos de higiene e princípios pedagógicos - e o desaparecimento do ensino profissional em Minas Gerais eram denunciados. Em contrapartida, exigiam do Estado instrução pública para todas as classes a fim de garantir desenvolvimento, ordem e conforto para os operários e a sociedade brasileira, e uma reforma da instrução, que deveria ser organizada segundo os ensinamentos pedagógicos mais modernos existentes naquele período. Ao mesmo tempo que cobrava solução estatal, a Confederação ofereceu aulas gratuitas em sua sede, as quais eram diurnas, para crianças (filhos dos sócios) de ambos os sexos, e noturnas, para os operários e sócios da Confederação.

5 CONFEDERAÇÃO AUXILIADORA DOS OPERÁRIOS DO ESTADO DE MINAS GERAIS. Constituição da Confederação Auxiliadora dos Operários do Estado de Minas Gerais. Belo Horizonte, 1911. 
Já o Centro Confederativo dos Operários $^{6}$ foi criado a partir das resoluções do Primeiro Congresso Operário Mineiro, sucedido em abril de 1907, em Sabará. O Centro defendia o "socialismo moderado ou con-

Figura 2 - Primeira página de O Confederal, de 2/5/1907. Fonte: CENTRO CONFEDERATIVO DOS OPERARIOS DO ESTADO DE MINAS. O Confederal, Belo Horizonte, número prospecto, 2 de maio de 1907. p. 1. temporâneo", sendo sua ação moderada, privilegiando esferas de negociações entre operários e patrões, e exigindo do Estado leis que melhorassem a situação do operariado. Sobre a atuação do Centro, Dutra (1988, p. 121) afirma que "ao que parece, o Centro Confederativo não se constituiu em elemento catalisador do movimento operário, nem em Minas nem em Belo Horizonte".

Originário de uma das determinações do Con-

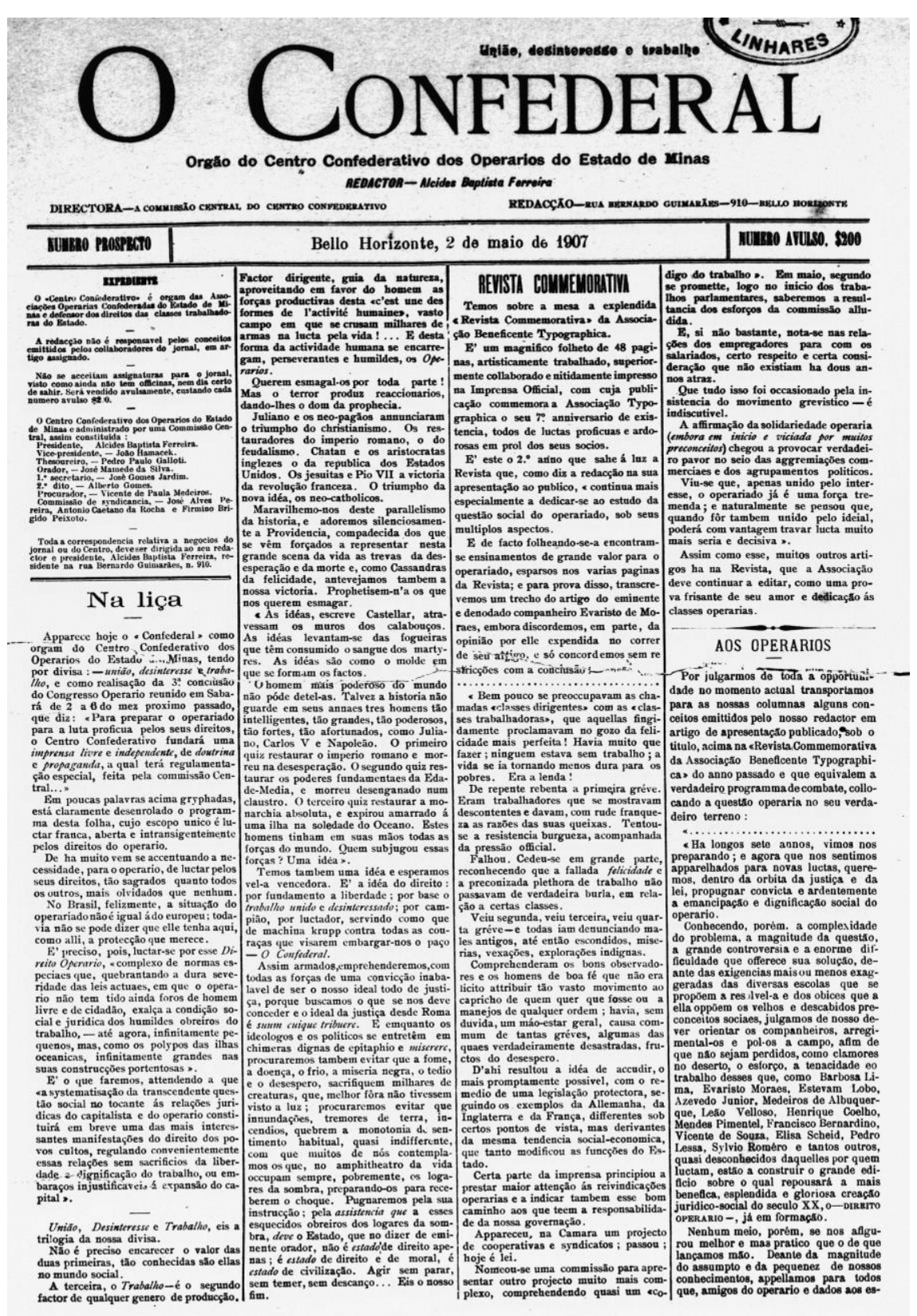

${ }^{6}$ O Centro Confederativo dos Operários, consoante Dutra (1988), a partir de 1912 passou a se chamar Confederação Operária Mineira. 
gresso Operário Mineiro e órgão do Centro Confederativo dos Operários, O Confederal teve cinco edições publicadas entre maio e agosto de 1907, sem periodicidade definida, e sob direção de Alcides Batista Ferreira que, além de diretor do Centro, era redator do periódico. Sob a divisa "união, desinteresse e trabalho", o jornal se declarava livre e independente de doutrina e propaganda, e seu maior objetivo era lutar pelo direito operário. Nos primeiros números privilegiou propagar ideias e conclusões do referido Congresso, mas também trazia notícias pertinentes ao operariado, relatava a formação e desenvolvimento de associações em Belo Horizonte e outros locais, informava sobre festividades, apresentava anúncios, etc. De orientação socialista, o Centro e seu jornal, como meio de alcançar o direito operário, propugnavam a instrução dos operários e de seus filhos, assim como a eleição de representantes que deveriam concorrer às eleições municipais para defesa dos direitos operários e "influir diretamente na administração do Estado, para poder alcançar as reformas necessárias e reclamadas para a afirmação prática e efetividade de seus direitos".7

Nas páginas de $O$ Confederal, a instrução era elencada como principal meio para solucionar os problemas operários em Minas Gerais. O Centro e seu jornal entendiam que a "ignorância" e o "obscurantismo" eram fatores de degradação da humanidade. Nesse sentido, o operário para agir enquanto cidadão que compreendia seu valor e direitos como homem livre - deveria se educar e instruir, caso contrário, seria um boneco movido aos acenos de alguns políticos. Por isso, conclamavam as associações a fazerem guerra contra o analfabetismo, trabalhando para difundir instrução e educação entre os operários.

No periódico era declarado o objetivo de cobrar do governo mineiro a fundação de escolas noturnas nos centros fabris, de escolas profissionais e de belas artes, a concessão de auxílios governamentais para as escolas livres fundadas por associações em suas sedes, e a gratuidade de matrícula dos filhos dos operários em estabelecimentos de ensino secundário e superior.

7 CENTRO CONFEDERATIVO DOS OPERÁRIOS DO ESTADO DE MINAS. $O$ Confederal, Belo Horizonte, número prospecto, 2 de maio 1907, p. 1. 
Outra pauta interessante era a exigência para que o governo decretasse a obrigatoriedade efetiva da frequência nas escolas primárias do Estado, criando, inclusive, penalidades para aqueles pais que, por ignorância ou incompreensão do valor da educação, não enviassem seus filhos para as escolas.

Ainda que a obrigatoriedade 8 do ensino primário fosse matéria legislativa estadual republicana presente desde a Constituinte Mineira (1891), reforçada, segundo Mourão (1962), nas reformas de ensino promovidas pelos sucessivos governos estaduais mineiros, nas quais eram previstas inclusive multas aos pais e responsáveis por crianças não matriculadas em escolas, é importante problematizar se os trabalhadores desconheciam os dispositivos legais, ou se esses na prática não funcionavam.

Apesar de prevista no projeto arquitetônico de Belo Horizonte, a estrutura escolar da instrução pública somente se organizou após sua inauguração e, principalmente, no início do século XX com o surgimento dos grupos escolares durante o governo do Estado de João Pinheiro (1906-1910) e de sua Reforma do Ensino Primário e Normal, de 1906. O objetivo do empreendimento desse governante coadunava com a ideia de formar "um povo instruído e regenerado para a nova vida". (VEIGA, 2002, p. 310). Os seus pressupostos se relacionam com o ideário republicanista brasileiro, segundo o qual

A escola é concebida como instrumento de civilização, o ensino público é avaliado como padrão para se medir o progresso e a moralidade de um povo, a instrução é base fundamental para o verdadeiro progresso social (...). (ARAÚJO; SOUZA; PINTO, 2013, p. 131-132).

Para Luciano Mendes de Faria Filho e Vera Lúcia Nogueira (2011, p. 538), essa reforma "destinada à parcela mais pobre da população mineira (...) deu uma nova feição ao ensino primário, com a criação dos

${ }^{8}$ Esta prescrição legal, segundo as reformas da instrução pública, era direcionada às crianças nas seguintes faixas etárias: de 7 a 13 anos, para ambos os sexos (1892, 1899, 1900); meninos de 7 a 14 anos, e meninas de 8 a 12 anos (1906); de 7 a 14 anos para ambos os sexos (1911, 1920, 1924, 1927). 
grupos escolares, reinventando, portanto, a escola mineira.”

A reforma buscou ser uma alternativa às escolas isoladas ao instituir os grupos escolares em Minas Gerais, considerada em sua materialidade (suntuosidade dos prédios dos grupos escolares, boa localização, etc.) "um espetáculo de racionalidade e de civismo". (VEIGA; FARIA FILHO, 1997, p. 216).

Alessandra Frota Schueler, Elizabeth Figueiredo de Sá e Maria do Amparo Borges Ferro (2013) apontam que, a despeito da defesa nos discursos dos presidentes dos estados brasileiros dos grupos escolares como a mais moderna forma de escola primária, essa se manifestou timidamente até a década de 1920, momento em que as escolas isoladas ainda eram maioria. As autoras revelam, a título de exemplificação, a existência de 171 grupos escolares e 1.566 escolas isoladas em Minas Gerais no ano de 1922.

De acordo com Cynthia Greive Veiga (2002, p. 330), "a hierarquização da ocupação da cidade corresponde à hierarquização do acesso ao saber”, o que significa dizer que o próprio ordenamento urbano de Belo Horizonte interferiu na abertura de grupos escolares, que seguiram a lógica da racionalidade partindo do centro (zona urbana) em direção a periferia (zona suburbana).

Seguindo esse pressuposto, entre 1907 e 1910, Belo Horizonte contava com três grupos escolares localizados na zona urbana: Barão do Rio Branco (1907)9 , Afonso Pena (1907) e Cesário Alvim (1909)10. Já o quarto grupo escolar, Francisco Sales (1911), foi construído no bairro Barro Preto, área naquele tempo residida por trabalhadores que se localizava no limite entre a zona urbana e suburbana, donde percebe-se a inicial expansão dessas instituições para além da região central. A partir de então, outros grupos escolares foram inaugurados na zona suburbana ou no seu limite. ${ }^{11}$

9 O Grupo Escolar Barão do Rio Branco funcionou até 1914 onde atualmente está localizada a Escola Estadual Afonso Pena. A partir dessa data foi transferido para prédio próprio no bairro Funcionários.

10 O prédio do Grupo Escolar Cesário Alvim somente foi inaugurado em 1930. Antes disso, o grupo funcionou provisoriamente em outros locais.

11 Tais como: Grupo Escolar Barão de Macaúbas (1914), no Floresta; Grupo Escolar 
Contudo, segundo Faria Filho e Nogueira (2011), a instrução primária noturna de trabalhadores já existia em Minas Gerais desde o século XIX, sofrendo retração em seu movimento de expansão a partir dos anos finais do século XIX, e retomando seu desenvolvimento com as reformas educacionais que ocorreram após $1906^{12}$. Em 1917, inclusive, foi criado o primeiro grupo escolar noturno do Estado, o Assis das Chagas ${ }^{13}$.

Nessa conjuntura, as associações operárias desempenharam um importante papel, já que algumas delas mantiveram escolas (diurnas e noturnas) destinadas aos trabalhadores e seus filhos, em suas sedes ou nos centros fabris. Dentre essas associações, a Confederação Auxiliadora dos Operários e o Centro Confederativo dos Operários.

Para Faria Filho e Nogueira, essas escolas vinculadas às associações empreendiam, única e exclusivamente, a alfabetização dos operários, não pretendendo ser lugar de doutrinamento político. No entanto, a respeito da iniciativa dos trabalhadores no estabelecimento de escolas, dizem:

Agentes indispensáveis na promoção das mudanças e na reivindicação de seus direitos, articularam, para isso, uma intensa vida associativa, via organização e mobilização da classe trabalhadora, buscando na instrução e na educação os principais instrumentos de luta e defesa de seus direitos. (FARIA FILHO; NOGUEIRA, 2011, p. 553).

Ao tratar sobre recente crescimento do campo de pesquisa da

Bernardo Monteiro (1914), no Calafate; Grupo Escolar Henrique Diniz (1914), no Santa Efigênia; Grupo Escolar Silviano Brandão (1914), no Lagoinha; Grupo Escolar Sandoval de Azevedo (1928), no Horto; Grupo Escolar Mariano de Abreu (1929), no Cachoeirinha; Grupo Escolar Lúcio dos Santos (1929), no Carlos Prates; Grupo Escolar Diogo de Vasconcelos (1930), no Floresta; Grupo Escolar Flávio dos Santos (1930), no Floresta; Grupo Escolar José Bonifácio (1930), no Santa Tereza; Grupo Escolar Professor Caetano Azeredo (1930), no Barro Preto; etc.; além de outros grupos escolares criados na área central - Olegário Maciel (1925) e Pedro II (1926) e das escolas isoladas e escolas reunidas dispersas pela cidade e que coexistiram junto aos grupos escolares.

12 De acordo com a Reforma João Pinheiro, regulamentada pelo decreto $\mathrm{n}^{0} \mathbf{1 . 9 6 0}$, de 16 de dezembro de 1906, era obrigação do governo a criação de escolas noturnas para adultos, desde que a frequência mínima fosse de 30 alunos.

13 O Grupo Escolar Assis das Chagas foi criado pelo decreto $\mathrm{n}^{\circ} 4.726$, de 21 de março de 1917. Funcionou nas dependências do Grupo Escolar Cesário Alvim até 1937, e depois foi transferido para as dependências do Grupo Escolar Olegário Maciel. 
história da educação brasileira, Faria Filho indica algumas temáticas de pesquisa pouco estudadas pela historiografia da educação mineira que, todavia, são de primordial importância. Dentre as possibilidades de pesquisa encontram-se aquelas que perpassam a educação infantil, a instrução secundária, e a educação operária:

(...) muito ainda precisamos avançar nas investigações sobre a educação de jovens e adultos numa perspectiva da história da educação. $O$ que sabemos a esse respeito limita-se quase exclusivamente as políticas e às campanhas de alfabetização ou, ainda, à história de algumas poucas instituições de marcado perfil profissionalizante. Muito pouco sabemos sobre as escolas noturnas abertas, desde o século XIX, para instruir jovens e adultos trabalhadores ou sobre as escolas organizadas pelo movimento operário para a educação da população trabalhadora analfabeta. (FARIA FILHO, 2008, p. 91-92).

\section{Considerações finais}

Este artigo buscou tratar da importância dos impressos operários, em particular, para as pesquisas em história da educação, discutindo algumas ideias educacionais contidas nos jornais $O$ Labor (Confederação Auxiliadora dos Operários) e $O$ Confederal (Centro Confederativo dos Operários), nos primeiros anos de existência de Belo Horizonte.

A fonte impressa, cada vez mais utilizada pela história da educação, foi apreendida como agente, que narra e intervêm nos acontecimentos, produzindo e divulgando ideias, valores, consensos, tensões, disputas, etc. Ainda assim, a imprensa operária apresenta particularidades que foram destacadas segundo concepções de autores que a tomam como fonte ou objeto de pesquisa em seus trabalhos.

Com seus impressos, os operários se informavam e, ao mesmo tempo, manifestavam opiniões e tendências políticas, elaboravam propostas, e pleiteavam a conquista de direitos, intervindo no cotidiano das cidades. É nessa atmosfera que as propostas educacionais contidas em $O$ Labor e $O$ Confederal foram investigadas.

A partir de análise preliminar - visto que a pesquisa se encontra 
em andamento - desses impressos foi apurada a existência de reivindicações e propostas operárias em prol de uma educação ampla e gratuita a todas as classes sociais. Conclui-se, que o ensino em Belo Horizonte não era ofertado a todos, ou se era oferecido, não alcançava as classes sociais menos favorecidas. Por isso, era necessário lutar por sua conquista - que só ocorreria décadas mais tarde - e, simultaneamente, propor formas educacionais alternativas. Além disso, a educação era entendida pelos operários como meio para a conquista de seus direitos e, portanto, fator de progresso geral da sociedade brasileira.

\section{Referências}

ARAÚJO, J. C. S; SOUZA, R. F.; PINTO, R. N. A escola primária e o ideário republicanista nas mensagens dos presidentes de Estado: investigações comparativas (1893-1918). In: SOUZA, R. F. (org.). Por uma teoria e uma história da escola primária no Brasil: investigações comparadas sobre a escola graduada (1870-1930). Cuiabá: EdUFMT, 2013, p. 105-145.

BASTOS, M. H. C. Espelho de papel: a imprensa e a história da educação. In: ARAÚJO, J. C.; GATTI JR., D. (org.). Novos temas em história da educação brasileira: instituições escolares e educação na imprensa. Campinas/Uberlândia: EDUFU, 2002, p. 151-174.

CARVALHO, C. H.; ARAUJO, J. C. S.; NETO, W. G.. Discutindo a história da educação: a imprensa enquanto objeto de análise histórica (Uberlândia-MG, 1930-1950). In: ARAÚJO, J. C.; GATTI JR., D. (org.). Novos temas em história da educação brasileira: instituições escolares e educação na imprensa. Campinas/Überlândia: EDUFU, 2002, p. 67-89.

COBEN, I. S. Diversificação e segmentação dos impressos. In: MARTINS, A. L.; LUCA, T. R. (org.). História da imprensa no Brasil. São Paulo: Contexto, 2013, p. 103-130.

CRUZ, H. F.; PEIXOTO, M. R. C. Na oficina do historiador: conversas sobre história e imprensa. Projeto História, São Paulo, n. 35, p. 255-272, 2007. 
DARNTON, R.; ROCHE, D. (org.). Revolução impressa: a imprensa na França, 1775-1800. São Paulo: EDUSP, 1996.

DECCA, M. A. A vida fora das fábricas: cotidiano operário em São Paulo (1920-1934). Rio de Janeiro: Paz e Terra, 1987.

DUTRA, E. F. Caminhos operários nas Minas Gerais: um estudo das práticas operárias em Juiz de Fora e Belo Horizonte na Primeira República. Belo Horizonte: Ed. UFMG, 1988.

FARIA, M. A.; GROSSI, Y. S. A classe operária em Belo Horizonte: 18971920. In: SEMINÁRIO DE ESTUDOS MINEIROS, 5, 1982, Belo Horizonte. Anais... Belo Horizonte: Faculdade de Filosofia e Ciências Humanas da UFMG, 1982, p. 165-213.

FARIA FILHO, L. M.; NOGUEIRA, V. L. A escola primária noturna na política educacional mineira (1891-1924). In: FONSECA, T. N. L.; VEIGA, C. G. História da Educação: temas e problemas. Belo Horizonte: Mazza, 2011, p. 532-555.

FARIA FILHO, L. M. O jornal e outras fontes para a história da educação mineira do século XIX: uma introdução. In: ARAÚJO, J. C.; GATTI JR., D. (org.). Novos temas em história da educação brasileira: instituições escolares e educação na imprensa. Campinas/Uberlândia: EDUFU, 2002, p. 133-150.

. O processo de escolarização em Minas Gerais: questões teóricometodológicas e perspectivas de pesquisa. In: VEIGA, C. G.; FONSECA, T. N. L. (org.). História e Historiografia da Educação no Brasil. Belo Horizonte: Autêntica, 2008, p. 77-97.

FERREIRA, M. N. A imprensa operária no Brasil: 1880-1920. São Paulo: Ática, 1988.

HARDMAN, F. F.; LEONARDI, V. História da indústria e do trabalho no Brasil: das origens aos anos vinte. São Paulo: Ática, 1991.

LUCA, T. R. História dos, nos e por meio dos periódicos. In: PINSKY, C. B. (org.). Fontes Históricas. São Paulo: Contexto, 2006, p. 111-153.

MACIEL, L. A. "Imprensa de trabalhadores, feita por trabalhadores, para trabalhadores"? História \& Perspectivas, Uberlândia, n. 39, p. 89-135, 2008b.

O popular na imprensa: linguagens e memórias. In: XIX ENCONTRO REGIONAL DE HISTÓRIA, 19, 2008, São Paulo. Anais... São Paulo: USP, 2008a.

MOURÃO, P. K. C. O ensino em Minas Gerais no tempo da República (1889-1930). Belo Horizonte: Centro Regional de Pesquisas Educacionais de Minas Gerais, 1962. 
PEREIRA, A. A Imprensa Operária no Brasil. Revista Novos Rumos, Marília, v. 5, n. 18/19, p. 82-88, 1990.

SCHUELER, A. F. M.; SÁ, E. F.; FERRO, M. A. B. A expansão da escola primária graduada nos estados na Primeira República: a ação dos poderes públicos. In: SOUZA, R. F. (org.). Por uma teoria e uma história da escola primária no Brasil: investigações comparadas sobre a escola graduada (1870-1930). Cuiabá: EdUFMT, 2013, p. 161-177.

VEIGA, C. G.; FARIA FILHO, L. M. Belo Horizonte: a escola e os processos educativos no movimento da cidade. Varia História, Belo Horizonte, n. 18, p. 203-222, 1997.

VEIGA, C. G. Cidadania e educação na trama da cidade: a construção de Belo Horizonte em fins do século XIX. Bragança Paulista: EDUSF, 2002.

\section{Fontes}

CENTRO CONFEDERATIVO DOS OPERÁRIOS DO ESTADO DE MINAS. O Confederal, Belo Horizonte, número prospecto, 2 de maio de 1907.

CONFEDERAÇÃO AUXILIADORA DOS OPERÁRIOS DO ESTADO DE MINAS GERAIS. Constituição da Confederação Auxiliadora dos Operários do Estado de Minas Gerais. Belo Horizonte, 1911.

CONFEDERAÇÃO AUXILIADORA DOS OPERÁRIOS DO ESTADO DE MINAS GERAIS. O Labor, Belo Horizonte, ano I, n. 1, 18 de jun. de 1905. MINAS GERAIS. Decreto $\mathrm{n}^{0}$ 1.960, de 16 dez. 1906. Aprova o Regulamento da Instrução Primária e Normal do Estado de Minas Gerais. Belo Horizonte, 1906.

MINAS GERAIS. Decreto ${ }^{0}$ 4.726, de 21 mar. 1917. Aprova a criação do Grupo Escolar Assis das Chagas. Belo Horizonte, 1917. 